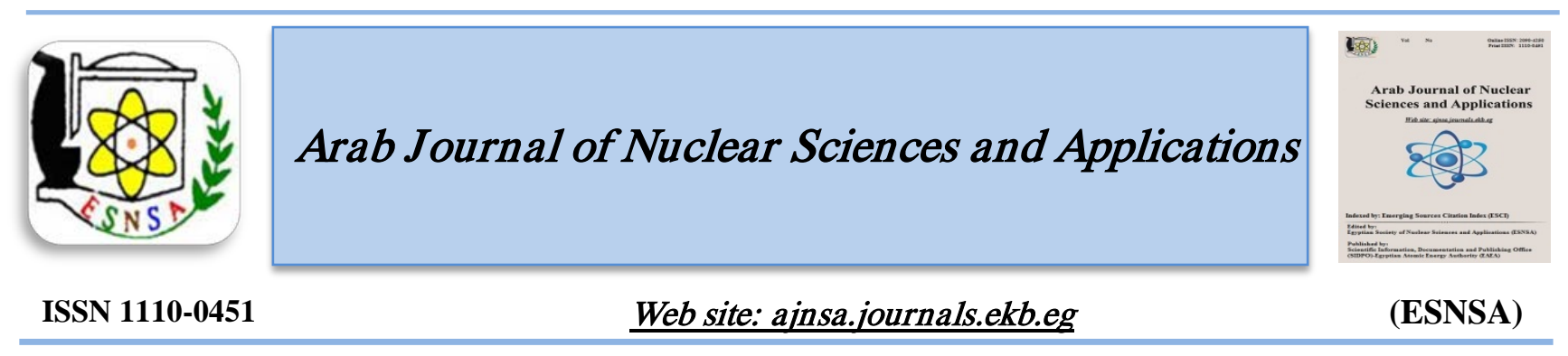

\title{
The Influence of Fire Retardant (Aluminum Hydroxide) Concentrations on EPDM Rubber Under $\gamma$ Irradiation
}

\author{
Samaa. A. Wasfy ${ }^{1}$, Elham M. Hegazi ${ }^{1}$, A.A. Abd El-megeed ${ }^{2}$, T. S. Mahmoud ${ }^{3}$, E.Y.El-Kady ${ }^{3}$ \\ (1) Nuclear \& Radiological Regulatory Authority, Cairo, Egypt \\ (2) National Institute for Standards, Cairo, Egypt \\ (3) Shobra Faculty of Engineering, Benha University
}

Received $17^{\text {th }}$ Sep 2017 EPDM is the most commonly used type of rubbers for cables insulation. In order to improve the EPDM Accepted $29^{\text {th }}$ Oct 2017 insulation rubber performance, many additives can be used. Aluminum hydroxide is used as a fire retardant because it is safe and cheap and reduces the amount of smoke produced in fires. In this study, two concentrations (10 and $20 \mathrm{phr}$ ) of aluminum hydroxide ATH were used to improve EPDM insulation properties and to prolong its operational life. The effect of gamma doses (up to $600 \mathrm{KGy}$ ) on the mechanical, physical and thermal properties of EPDM/ ATH has been investigated. The results of the present study show that the optimum concentration of ATH is $20 \mathrm{phr}$.

Keywords: EPDM, ATH, Gamma ray

\section{Introduction}

A variety of environmental stressors in nuclear power plants (NPPs), such as temperature, radiation, humidity, vibration, chemical spray, and mechanical stress, can influence the degradation of electrical power and instrumentation and control (I\&C) cables and their insulation. In the course of time, these stressors can lead to degradation of cables insulation which could lead to insulation failure of the associated components in case of inappropriate management. This could result in disabling cables to perform their intended safety function [1].

Polymers, as one of the developing and upcoming materials, are increasingly used in various industrial applications due to their wide range of properties. Some types of polymers are widely used in cable industry due to their flexibility, insulation properties and high limits of deformation. Rubber insulations and sheaths of electrical cables used in nuclear power plants are highly exposed to ionizing irradiations and relatively high temperatures, which may both considerably accelerate the aging process.

One of widely used is Ethylene propylene diene monomer rubbers EPDM, which should be crosslinked in order to reach an acceptable level of mechanical properties. However, pure elastomer network does not possess high mechanical properties and consequently their reinforcement is considered by adding fillers into the polymer matrix [2].

Owing to their excellent electrical and thermal insulation properties, EPDM are widely used in wire and cable coatings. The increasing demand for EPDM in electrical applications is also due to its excellent resistance to degradation and ease of accepting large amounts of fillers. Thus, formulations which use aluminum trihydroxide

Corresponding author: samaaahmedwasfy1812@yahoo.com

DOI: 10.21608/ajnsa.2018.6507

(c) Scientific Information, Documentation and Publishing Office (SIDPO)-EAEA 
(ATH) as fillers with good mechanical and ageing resistance, with flame retardancy and smoke suppression characteristics have been developed. These polymer materials, used in cables and accessories, can be exposed to severe environmental conditions. An example would be cables in nuclear power plants which may be exposed to elevated temperatures and gamma irradiation. These conditions are known to cause their ageing and consequently their degradation over time [3].

The addition of rigid filler particles, even in small amounts, to an elastomer, strongly influences its response to mechanical stimuli. Nano fillers are the ultimate choice in fillers because of their ability to modify properties at very low levels of incorporation [4].

In recent years, there has been an increasing interest in the use of nano metal oxides as reinforcing fillers [5]. Alumina is one of the important ceramic materials. Nano crystalline $\mathrm{Al}_{2} \mathrm{O}_{3}$ powder has a considerable potential for a wide range of applications including high strength materials, electronic ceramics and catalysts.

In order to modify the properties of EPDM insulated rubber for cables and wires used for NPPs, it may be required to add suitable additives to increase mechanical, physical, and thermal properties. Fillers are used commercially in industrial processing of rubber formulation due to its specific characteristics and suitable price [6].

In many structural applications, flame retardant additives are added to improve the flame retardancy characteristics of polymers. Aluminum hydroxide (ATH) is gaining special interest because of its low toxicity, good smoke suppression ability and less corrosiveness actions. Up till now much work has been published on polyethylene/ flame retardant composites [7, 8, 9, 10], but no study has been carried out to investigate the effect of gamma irradiation on the fate of incorporated additives during irradiation. The flame retardant synergism between $\mathrm{MH}$ and SP was studied [11]. The effect of gamma radiation on the thermo-mechanical properties of those composites was studied. In addition, radiation-induced structural and morphological changes were also studied. [12]

\section{Experimental}

\section{Materials}

The materials used in the present work are of commercial grade of EPDM (ethylene-propylene rubber; Herlene, grade HS63) manufactured by Unimers India Limited (in collaboration with Uniroyal Chemical Co., USA. And ATH(Aluminum Hydroxide $\mathrm{Al}(\mathrm{OH})_{3}$ Oxford Laboratory .Other rubber additives such as stearic acid, zinc oxide, processing oil, antioxidant, and sulfur were of commercial grades. All the materials used in this search come from El Nasr Pharmaceutical Chemicals Co. Cairo, Egypt.

\section{Preparation of samples and irradiation}

EPDM rubber samples are mixed with different amounts of ATH, the compounding recipe is given in Table 1 . The mixing of the rubber is carried out on a laboratory two-roll mill (Farrel-UK,152 mm and $330 \mathrm{~mm}$ ) at a friction ratio of 1:1.4, according to ASTM D3182 [13] .The Oscillating Disk Rheometer (Alpha-UK, MDR 2000) measures the complete curing characteristics of an elastomer compound. Samples of about $5 \mathrm{~g}$ were cut from a milled sheet and placed in the rheometer, at a specified temperature according to ASTM D-2084 [14] at $160 \mathrm{C}^{0}$ for EPDM compounds. The samples were vulcanized in a hydraulic press (Farrel-UK) at $160 \mathrm{C}^{0}$ and a pressure of $150 \mathrm{~kg} / \mathrm{cm} 2$ for a period of $4.5 \mathrm{~min}$ for EPDM compounds. A C $0^{60}$ source of gamma facility Canadian Gamma Cell (Ge 220) represented at the National Center for Radiation Research and Technology (NCRRT) with rate 2 $\mathrm{KGy} / \mathrm{h}$ is used for gamma-irradiation.

\section{Swilling measurements}

Swelling experiment procedure according to ASTM D-471 [15] was carried out by immersing three circular samples cut from the rubber sheets with 5-mm diameter and 2-mm thick in toluene solvent for $48 \mathrm{~h}$ to reach equilibrium at room temperature. The swelling ratio, $Q(t) \%$, of the EPDM rubber in the solvent was calculated by the equation:

$$
Q(t) \%=\frac{M t-M i}{M i} \times 100
$$

Where Mi the initial weight of sample, Mt the weight of swollen sample. 
Crosslinking measurements

The most important changes of gamma irradiation effect in rubber is crosslinking (intermolecular bonds), and degradation (the scission of bonds in the main polymer chain and inside chains). The number of the formed crosslinks is proportional to the dose rate. The crosslinking, $v_{e}$, of the EPDM rubber compounds was calculated by the equation:

$$
v_{e}=\rho_{r} N / M_{C}
$$

Where $\rho_{\mathrm{r}}$ : the density of the rubber

$\mathrm{N}$ : Avogadro's number $=6.02214179 \times 10^{23} \mathrm{~mol}^{-1}$ $\mathrm{M}_{\mathrm{c} \text { : }}$ the average molecular weight between crosslinks of rubber and can be calculated according to the theory of Flory and Rehner [16] by:

$\mathrm{M}_{\mathrm{C}}=-\mathrm{V}_{1} \rho_{\mathrm{r}}\left\{\Phi_{\mathrm{r}}^{1 \beta}-\Phi_{\mathrm{r}} / 2\right\} /\left\{\ln \left(1-\Phi_{\mathrm{r}}+\Phi_{\mathrm{r}}+\right.\right.$ $\mu \Phi_{\mathrm{r}}^{2\}}$

Where $\mathrm{V}_{1}$ the molar volume for toluene $=106.3$ $\mathrm{cm}^{3} /$ mole.

$\Phi_{\mathrm{r}}$ the volume fraction of polymer and can be determined from the equilibrium degree of swelling $\mathrm{Q}_{\mathrm{m}}$ as follows:

$\mathrm{Q}_{\mathrm{m}}=1 / \Phi_{\mathrm{r}}=1+\left\{\mathrm{M}_{\mathrm{s}} \rho_{\mathrm{r}} / \mathrm{M}_{\mathrm{r}} \rho_{\mathrm{s}}\right\}$

Where $M_{r}$ and $M_{S}$ are the weights of dried rubber and absorbed solvent, respectively, also, $\rho_{s}$ and $\rho_{r}$ are the densities of the solvent used and the rubber compound, respectively.

$\mu$ : the Huggins [17] interaction parameter between solvent and polymer and it can be calculated as:

$\mu=\left(\delta_{\mathrm{s}}-\delta_{\mathrm{r}}\right)^{2} \mathrm{~V}_{1} / \mathrm{R} \mathrm{T}$

Where $\delta_{s}$ and $\delta_{r}$ are the solubility parameters of the solvent and rubber compounds respectively.

$\mathrm{R}$ : the Universal gas constant $=8.314 \mathrm{~J} \cdot \mathrm{K}^{-1} \cdot \mathrm{mol}^{-1}$

$\mathrm{T}$ : the absolute temperature.

\section{Mechanical tests}

The tensile strength and elongation at break are measured using a Zwick (Germany) Tensile Testing Machine (Model Z010) at a crosshead speed of $500 \mathrm{~mm} / \mathrm{min}$ using five dumb-bell tensile specimens being shaped according to ASTM D-
412 [18]. The hardness test is measured by a Shore Hardness Tester Machine (TH200) according to ASTM D-2240 [19].

\section{Thermal Tests}

Thermo gravimetric analysis was performed using TGA -50H( NCRRT ) from room temperature to $600^{\circ} \mathrm{C}$ under nitrogen atmosphere at a flow rate 20 $\mathrm{ml} / \mathrm{min}$, and heating rate $10{ }^{0} \mathrm{C} / \mathrm{min}$, two samples at different doses were tested to determined their thermal stabilities.

\section{Results and Discussion}

Polymeric materials such as polypropylene (PP), polyethylene (PE) and ethylene propylene diene monomer (EPDM) are widely used as insulators for cable applications. ATH is a popular flame retardant because of its cost-benefit and low toxicity $[20,21]$. There are many reports on the suitability of ATH as a flame retardant for wire and cable insulation. Besides that, ATH has other advantages such as smoke suppression, optical translucency, thermal conductivity and chemical stability [22, 23, 24, and 25]. ATH is also capable of reducing the product cost due to its relatively cheaper price than that of the polymers [26].

The effect of the presence of ATH filler on the change of the mechanical and physical properties of ATH filled EPDM after ageing by gamma irradiation at room temperature is studied. All samples were exposed to gamma radiation of a $\mathrm{Co}^{60}$ source at a dose rate of $2 \mathrm{kGy} / \mathrm{h}$ in an oxygen atmosphere for doses 50,100,200,400 and 600 kGy. The results show that EPDM filled with ATH as an additive gives the best physical, mechanical, and thermal performance rather than unfilled EPDM.

\section{ATH Characterization}

The curves representing the particle size distribution show similar patterns for ATH (Fig.1), and Average particle size of ATH particles shows in Table 1.

\section{Swelling properties}

Fig. (2) shows the swelling ratio for EPDM/ ATH compound (EA0, EA1, and EA2) at different gamma doses. Fig 2 shows that generally the swelling ratio decreases with increasing gamma doses. However, the present results show that EA1 (EPDM with $10 \mathrm{phr}$ ATH) have lowest value of 
swelling ratio while EA2 (EPDM with $20 \mathrm{phr}$ ATH) has the highest value.

Determination of the swelling ratio of the radiation vulcanized EPDM rubber was carried out, and the results are shown in Fig. (2).The restriction of swelling has already been recognized to be related to the amount of ATH and the gamma doses. From the results, the EPDM rubber sample with 20phr of ATH have high swelling ratio at lower doses up to 200KGy and it decreases slightly with increasing in the doses up to 600KGy.This change is due to the crosslinking density. The most important effect of gamma irradiation on rubber is crosslinking (intermolecular bonds), and/or degradation. It can be observed that the EPDM compounds swelled more at low doses and the swelling ratio decreases with increasing in gamma doses. The crosslinking density of rubber compounds increased as gamma doses increased as can be observed in Fig. (2). The present results showed that EA2 (EPDM rubber with 20phr of ATH) has lower values of crosslinking density.

Fig. (3) shows the effect of gamma rays on the crosslinking density of EPDM/ATH samples. The results of crosslinking density measurement of EPDM rubber showed that there is a slightly increasing in the crosslinking with increasing of gamma doses. All rubbers suffer modifications at their properties when exposure to gamma doses, a loss of their mechanical properties is obtained. The results show that EA2 has the lowest values of crosslinking density. This indicates that ATH has an effect in mechanical properties.

\section{SEM analysis}

JSM-6510LA, Analytical scanning electron microscope (SEM) was used to examine the fracture surfaces of the samples (Fig.4). Each sample was gold-coated prior to analysis. The images were obtained at an operating voltage of 20 $k V$. The SEM photographs in the Fig. show that the uniform dispersion of ingredients in polymer matrix for ES0 and ES2, that means the ATH fillers were distributed very well within the polymer matrix for $20 \mathrm{phr}$, but for $10 \mathrm{phr}$ ATH, the SEM shows non-uniform dispersion.

\section{Mechanical properties}

Tensile strength is mainly related to the stress distribution within rubber and the effective increase in the rupture path [27]. Fig. (5) shows that the effect of gamma irradiation doses on the tensile strength of different samples of EPDM rubber with ATH filler. It is clear from this Fig. that EA2 has the highest value, while EA0 and EA1 have the lowest values up to $600 \mathrm{KGy}$.

Fig. (6) shows the effect of gamma irradiation dose on the elongation at break (Eb) of different samples of EPDM rubber with ATH filler. It was clear that the Eb values show the maximum value for EA2 with and without gamma radiation effects. Also, Eb values for all rubber compounds slightly decrease with increasing the doses until 600 KGy.

From Fig. $(5,6)$, it is clear that an increase in the filler loading results in a pronounced increase in the tensile strength, and elongation at break, which indicates the reinforcement effect of the filler. However, they are in all cases much better in comparison with the unfilled sample, which indicate the lack of weak spots or in homogeneities in the filled rubbers [28].

The improved properties of small particle size ATH - filled EPDM samples can be related to the better dispersion of these small particle sizes of ATH, besides the strong filler-rubber interaction which led to improving the mechanical properties as clear from Fig. $(4,5)$. The peak values for tensile strength and elongation at break at $20 \mathrm{phr}$ for ATH can be attributed to the softening effect of these fillers in rubber compounds and the strong reinforcing efficiency. This indicates that structure and size of added small particle size fillers are the main factors controlling the improvement of rubber mechanical properties.

The elongation at break decreased with dose increasing for all samples due to more cross-linked structures produced in the sample matrix, which prevents the structural organization during drawing and brings about a decrease in internal chain mobility and elongation [29]. This observation further supports the explanation provided for the swelling ratio and crosslinking density behavior with high radiation dose discussed as mentioned above.

\section{Hardness properties}

Shore a Hardness measurement is the most common instruments used for rubber and 
elastomer hardness characterization. The measurement of changes in the hardness of materials can provide important measurement about the effects of gamma irradiation on the rubber material. Fig. (7) Shows the effect of $\gamma$ doses on the hardness of EPDM samples with and without ATH. From this Fig.it is clear that EA1 has the highest value; while EA2 has the lowest values up to $400 \mathrm{KGy}$. The present results show that the hardness increased with increasing in $\gamma$-doses for all EPDM compounds as a result of the increasing in the crosslinking density of the rubber.

\section{Thermal properties}

EPDM/ATH composites were chosen and tested to determine their thermal stabilities. Fig. 8 represents the TGA (thermogram) curve for
EPDM/ATH composites at different gamma doses, and the effect on their thermal stability.

From the fig.it is clear that the thermal stability of ES2 at 200KGy was slightly enhanced compared to uniradiated one, as the temperatures of first and main decomposition step were $428.83 \mathrm{C}$, and 467.96 C leaving 5.15\% char residue, which means that the radiation dose 200KGy enhanced the thermal stability for the sample ES2 (EPDM with $20 \mathrm{phr}$ ). This is attributed to the shielding effect of the ATH filler which shield radiation effects. Also, we show that the weight loss of the composite ES2 is less than the weight loss of EPDM without ATH.

Table (1): List of all ingredients of the mixture

\begin{tabular}{|c|c|c|c|}
\hline Ingredients (phr) ${ }^{\mathrm{a}}$ & EA0 & EA1 & EA2 \\
\hline EPDM & 100 & 100 & 100 \\
\hline Stearic acid & 2.5 & 2.5 & 2.5 \\
\hline Zinc oxide & 5.8 & 5.8 & 5.8 \\
\hline Oil & 10 & 10 & 10 \\
\hline MBTSc $^{b}$ & 2.4 & 2.4 & 2.4 \\
\hline $6 \mathrm{PPD}^{\mathrm{c}}$ & 2 & 2 & 2 \\
\hline Sulfur & 1 & 1 & 1 \\
\hline $\mathrm{CaC}^{\mathrm{d}}$ & 25 & 25 & 25 \\
\hline $\mathrm{ATH}^{\mathrm{e}}$ & 0 & 10 & 20 \\
\hline
\end{tabular}

a Part per hundred part by weight of rubber

b MBTSc Dibenthiazyl Disulfide

c 6PPD N-(1, 3-dimethylbutyl)-N'-phenyl-p-phenylene diamine

d $\mathrm{CaC}$ calcium carbonate

e ATH aluminum tri hydroxide

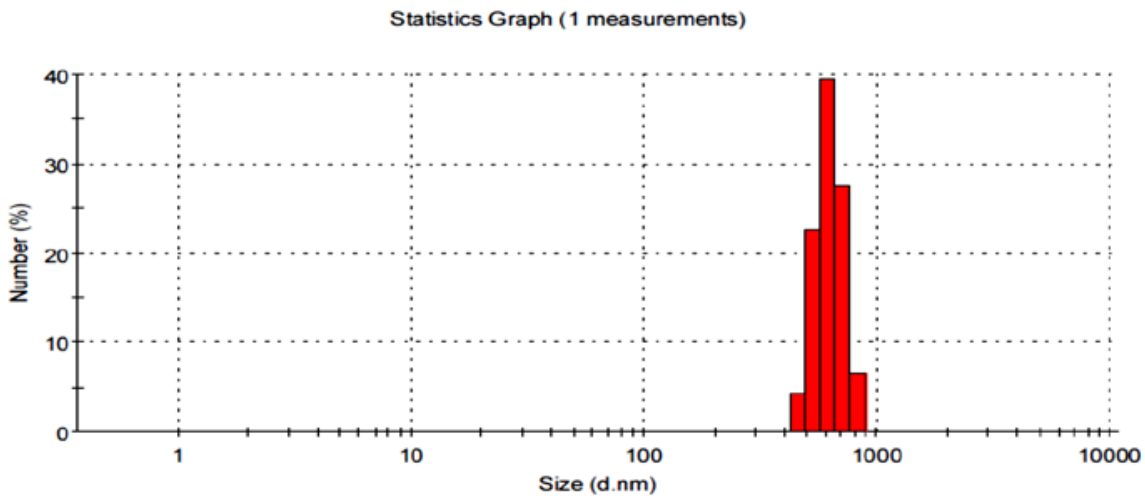

Fig. (1): particles size distribution of ATH 
Table (1): Average particle size of ATH particles

\begin{tabular}{cc}
\hline Diameter $(\mathrm{nm}) \%$ & ATH \\
\hline 4.1 & 458.7 \\
22.6 & 531.2 \\
39.4 & 615.1 \\
27.4 & 712.4 \\
6.5 & 825 \\
\hline
\end{tabular}

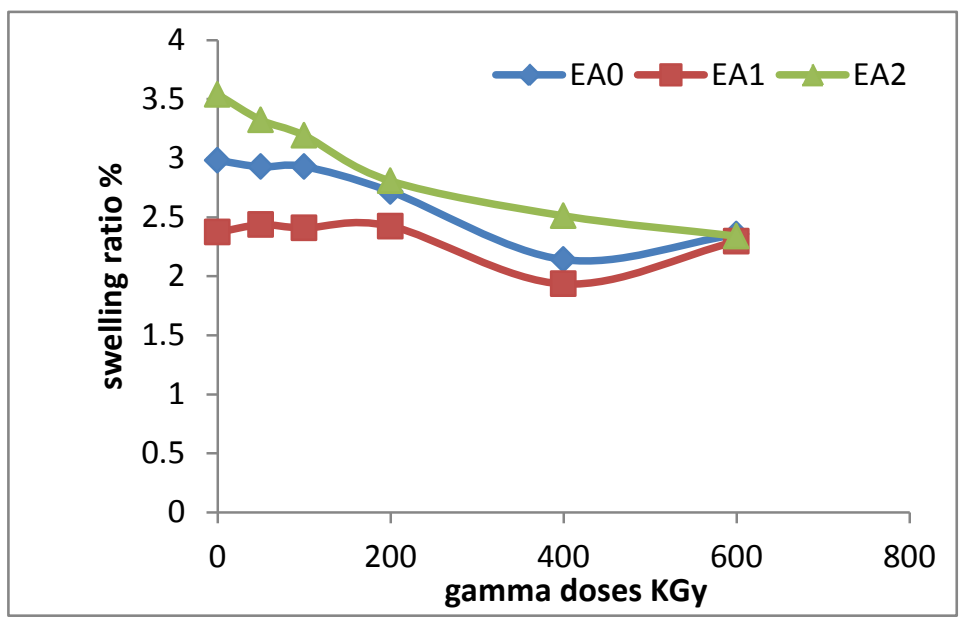

Fig. (2): Effect of gamma doses on swelling ratio of EPDM samples with ATH filler

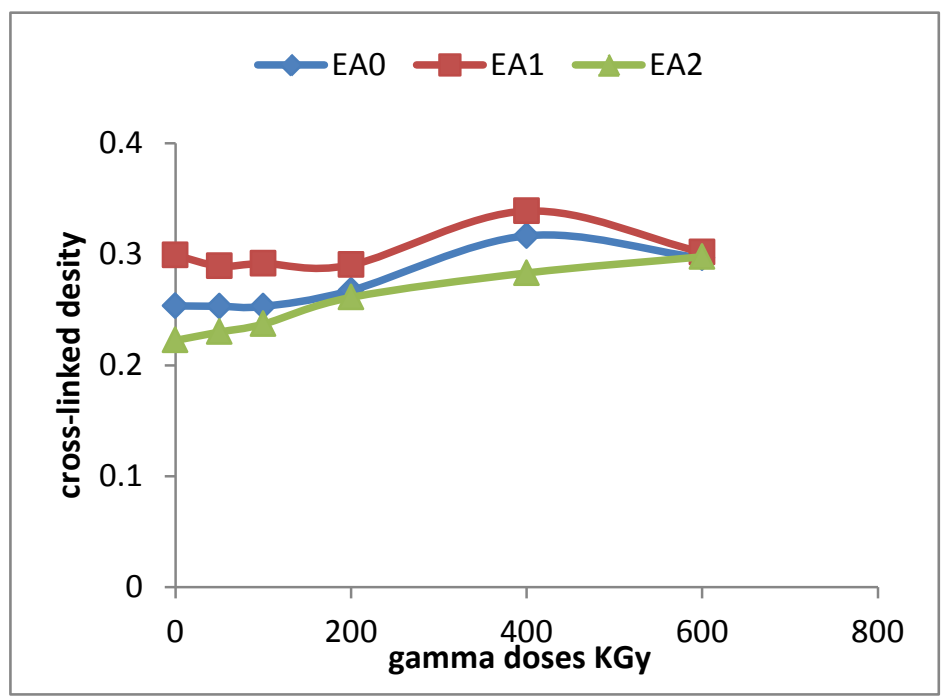

Fig. (3): Effect of gamma doses on crosslinking density of EPDM with ATH filler 


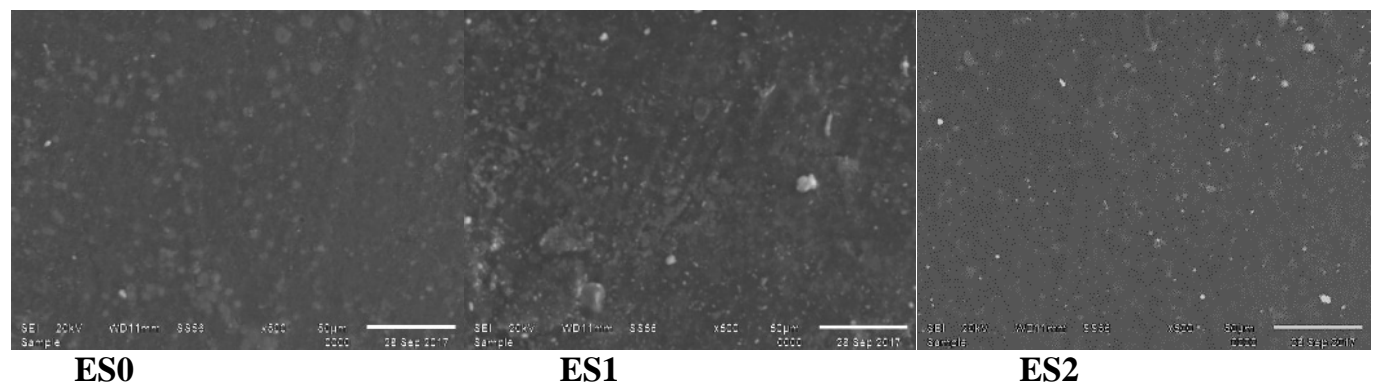

Fig. (4): SEM Analysis for sample of EPDM rubber composites with 0,10,and 20 phr ATH

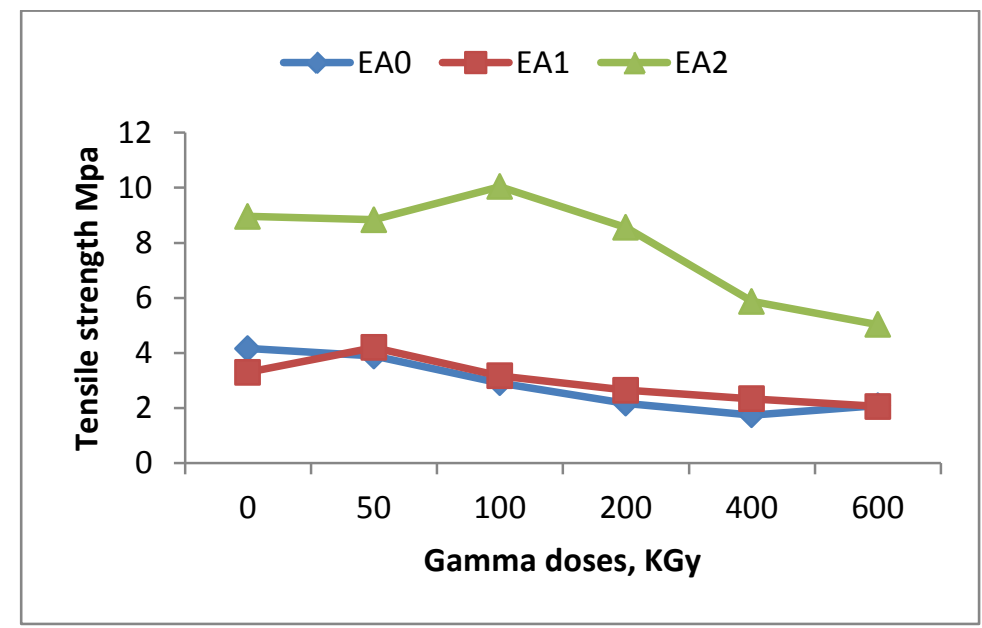

Fig. (5): Effect of gamma doses on tensile strength of EPDM samples with ATH filler

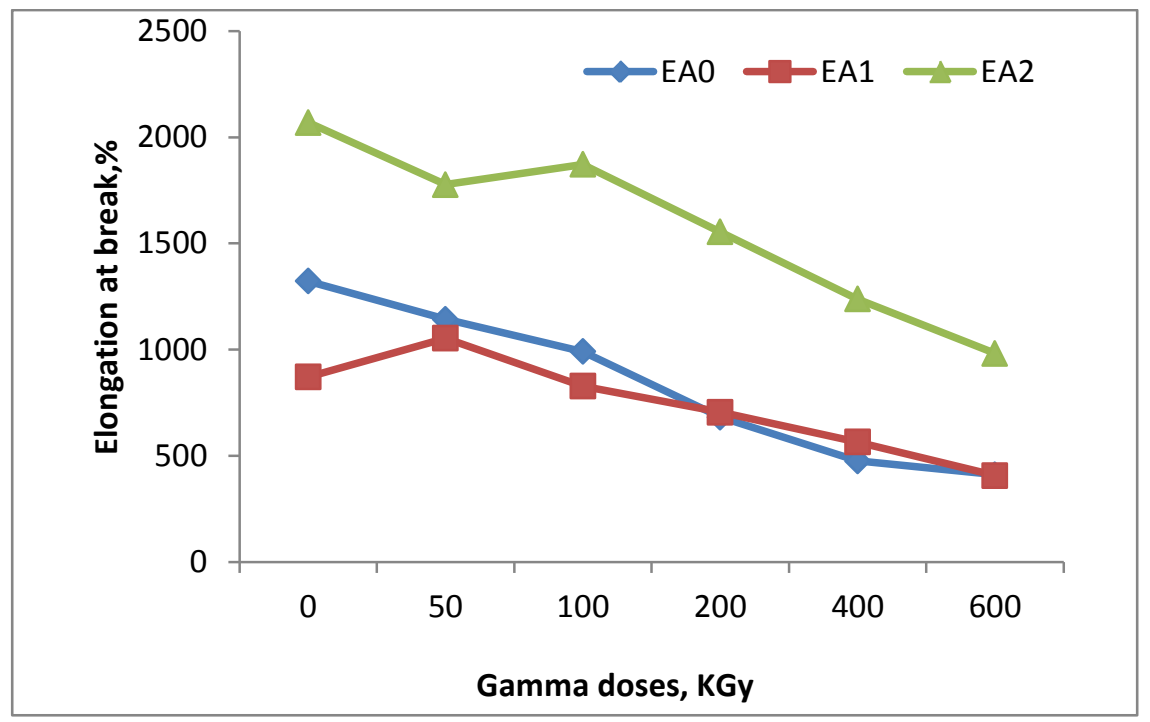

Fig. (6): Effect of gamma doses on elongation at break of EPDM samples with ATH filler 


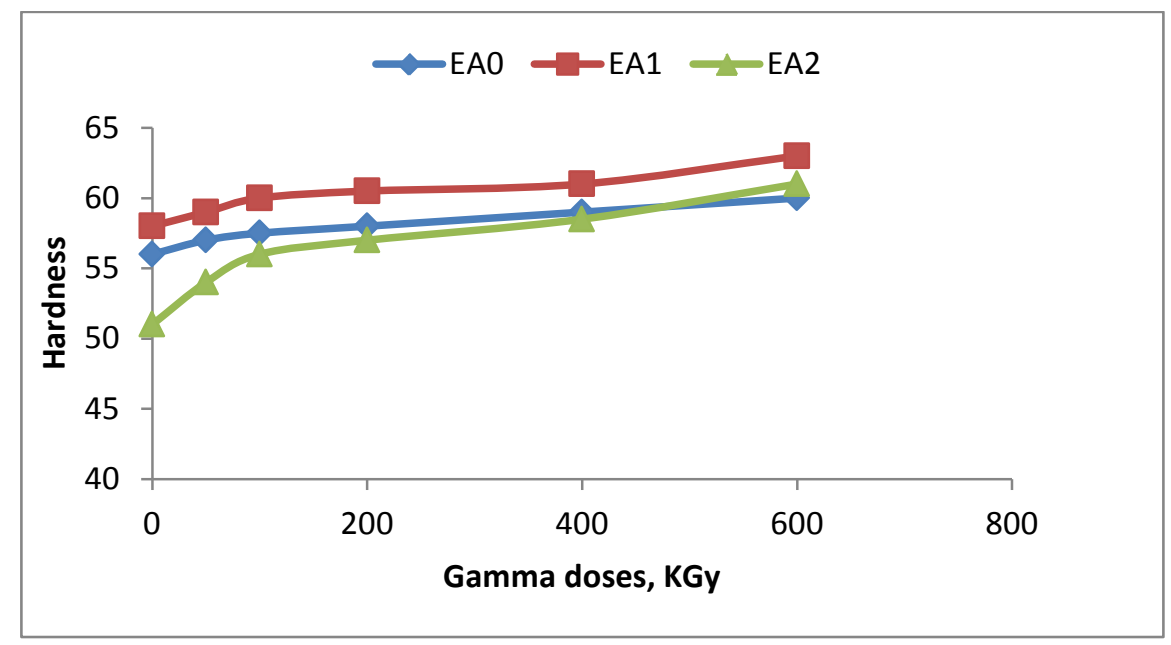

Fig. (7): Effect of gamma doses on hardness of EPDM samples with ATH filler

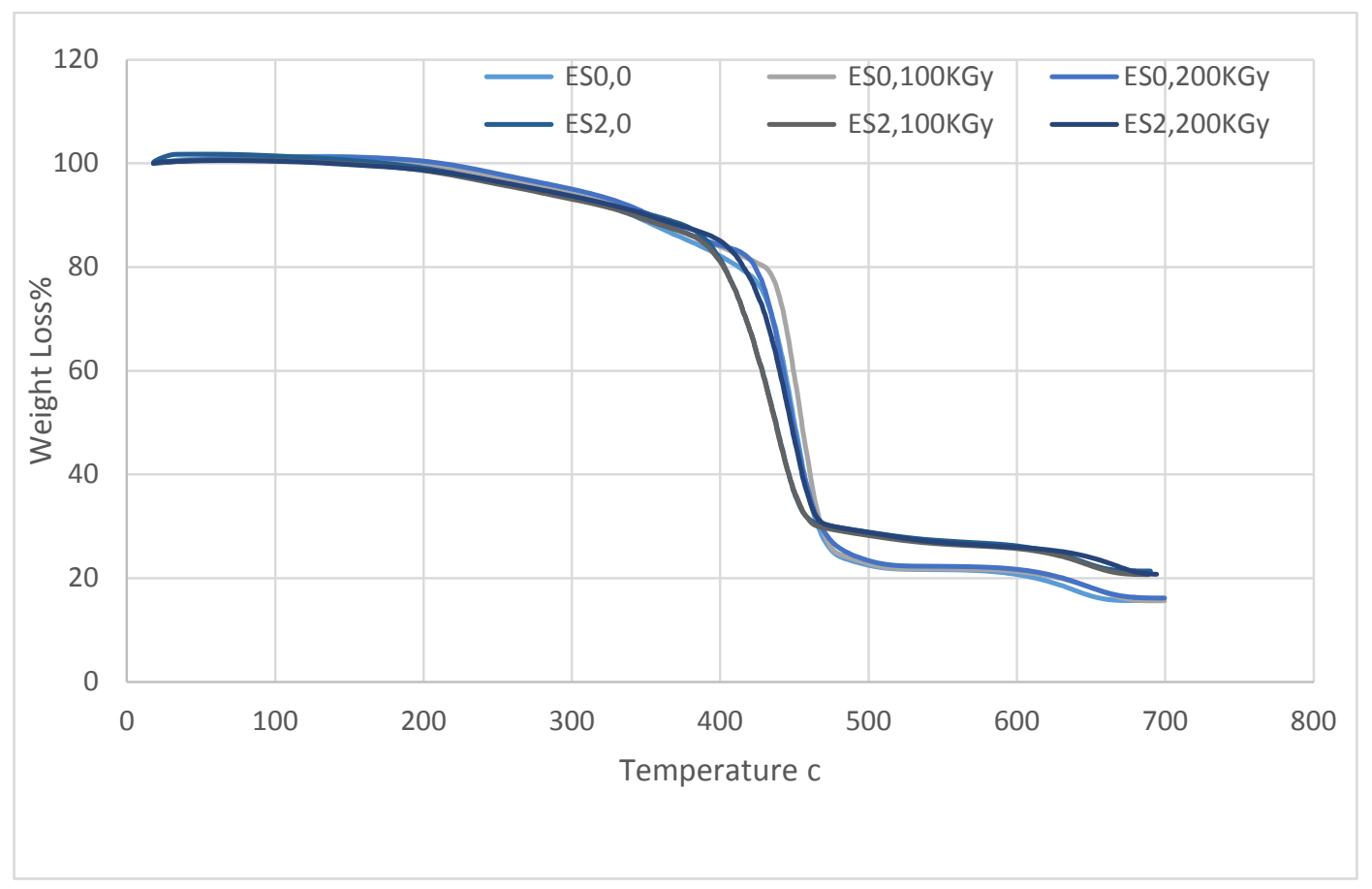

Fig. (8): TGA curve of rubber samples at different $\gamma$-doses

\section{Conclusions}

In the present study ATH are selected to study their effect on the physical and mechanical properties of EPDM rubber samples under gamma radiation up to $600 \mathrm{KGy}$. From the present results, it can be concluded that the addition of ATH to the EPDM rubber plays a good role in the performance of the EPDM rubber in terms of improving their physical, mechanical and thermal properties. EPDM with $20 \mathrm{phr}$ of ATH showed the best physical, mechanical, and thermal properties compared with the other two samples. It can be concluded that ATH represents a good additive improving the protective properties for the EPDM rubber insulating material used in nuclear facilities under gamma radiation. 


\section{References}

1- NUREG/CR, Expanded Materials Degradation Assessment (EMDA) Volume 5: Aging of Cables and Cable Systems -7153, Vol. 5, 2013

2- Amin Shabani, Thermal and Radiochemical Aging of neat and ATH filled EPDM: Establishment of Structure/Property Relationships, 2013.

3- Emilie Planes, Laurent Chazeau , Gérard Vigier , and Thomas Stuhldreier, Influence of silica fillers on the ageing by gamma radiation of EDPM nanocomposites, 2010.

4- Teena Thomas, Ayswarya E. P. and Eby Thomas Thachil, Nano Alumina as Reinforcement in Natural Rubber Composites, 2013

5- A. P. Meera, Sylvère Said, Yves Grohens, A. S Luyt and Sabu Thomas, "Tensile Stress Relaxation Studies of $\mathrm{TiO} 2$ and Nanosilica Filled Natural Rubber Composites Ind. Eng. Chem. Res., 48 (10), pp 5123-5123, 2009.

6- Sandra Regina Scagliusi, Elisabeth Carvalho Leite Cardoso, Traian Zaharescu Ademar Benévolo Lugão, Influence of Gamma Radiation on EPDM Compounds Properties For Use In Nuclear Plants”, American Institute of Physics,AIP Conference Proceedings 1779, 080015, (2016).

7- Mai Mahmoud Mohamed EL-Zayat, Radiation Curing of Rubber/Thermoplastic Composites Containing Different Inorganic Fillers,thesis, 2012.

8- Mohammed A. Bahattab, Jaroslav Mosnáček Ahmed A. Basfar Email, andTariq M. Shukri, Crossliked poly (ethylene vinyl acetate)/low density polyethylene (LDPE)/metal hydroxides composites for wire and cable applications , 2010.

9- Hui Liu ,Zhengping Fang , Mao Peng, Lie Shen, and Yong chang Wang The effect of irradiationcrosslinking on the thermal and flame-retardant properties of HDPE/EVA/ magnesium hydroxide composites, 2009.

10- Chuanmei Jiao, Zheng zhou Wang, Xilei Chen, Benyi Yu, Yuan Hu, Irradiation crosslinking and halogen-free flame retardation of EVA using hydrotalcite and red phosphorus , Radiation Physics and Chemistry, Volume 75, Issue 5, 2006.

11- Li. Z, Qi. B., Effect of gamma irradiation on the properties of flame-retardant EVM/magnesium hydroxide blends, 2004.

12- , Rahmat Gul, Atif Islam, Tariq Yasin, Sadullah Mir ,Flame-retardant synergism of sepiolite and magnesium hydroxide in a linear low-density polyethylene composite, Wiley Online Library 2011 .

13- Muhammad Shafiq, Tariq Yasin, Effect of gamma irradiation on linear low density polyethylene/magnesium hydroxide/sepiolite composite, 2012

14- ASTM D-3182. Standard practice for rubber materials, equipment, and procedures for mixing standard compounds and preparing standard vulcanized sheets. Annual book of standards, vol. 09.01; 1994.

15- ASTM D-2084. Standard test method for rubber property-vulcanization usingoscillating disk cure meter; 1995.

16- ASTM D-3182. Standard practice for rubber materials, equipment, and procedures for mixing standard compounds and preparing standard vulcanized sheets. Annual book of standards, vol. $09.01 ; 1994$.

17- ASTM D-2084. Standard test method for rubber property-vulcanization usingoscillating disk cure meter; 1995.

18- ASTM D-471,Standard test method for rubber property-effect of liquids, 1998.

19- Flory PJ, and Rehner J., Statistical mechanics of swelling of crosslinked polymer networks. J Chem Phys 1943;11:512

20- Huggins ML. Solution of long chain compounds. J Chem Phys 1941.

21- Emilie Planes, Laurent Chazeau, Gérard Vigier, Jérôme Fournier,and Isabelle Stevenson-Royaud, Influence of fillers on mechanical properties of ATH filled EPDM during ageing by gamma irradiation. Polymer Degradation and Stability 95: 1029-1038. 2010.

22- Weinheim, Functional Fillers for Plastics. USA: Wiley-VCH Verlag GmbH \& Co .Xanthos, M. 2010.

23- Beyer, G. ,Filler blend of carbon nanotubes and organoclays with improved char as a new flame retardant system for polymers and cable applications. Fire and Materials 29: 61-69. 2005.

24- Kalyon, D.M., Electrical properties of composites as affected by the degree of mixedness of the conductive filler in the polymer matrix. Polymer Engineering and Science, 2002 .

25- Lee, C.H. \& Kim, S.W., Effects of particle size of $\mathrm{Al}(\mathrm{OH}) 3$ on electrical properties of EPDM compounds. Polymer Engineering and Science, 2000.

26- Olasz, L. \& Gudmundson, Prediction of residual stresses in cross-linked polyethylene cable insulation. Polymer Engineering and Science, 2005.

27- Reza Hashemi Farzad, Azman Hassan, M. Jawaid \& M.A.M. Piah, Mechanical Properties of Alumina Trihydrate Filled Polypropylene/Ethylene Propylene Diene Monomer Composites for Cable Applications, 2013

28- H.H. Hassan, E. Ateia , N.A. Darwish , S.F. Halim , A.K. Abd El-Aziz, Effect of filler concentration on the physico-mechanical properties of super abrasion furnace black and silica loaded styrene butadiene rubber, 2012.

29- Arroyo M, Organo-montmorillonite as substitute of carbon black in natural rubber compounds. 2003. 